\title{
Cardiac Valve
}

National Cancer Institute

\section{Source}

National Cancer Institute. Cardiac Valve. NCI Thesaurus. Code C12729.

Any of the four heart valves, including the two atrioventricular valves and the two semilunar valves, which regulate the flow of blood through the chambers of the heart. 